\title{
PEMANFAATAN LIMBAH ALUMINIUM SEBAGAI KOAGULAN DALAM PENGOLAHAN LIMBAH CAIR DAN PENJERNIHAN AIR
}

\author{
Afifah Rosyidah ${ }^{1}$ dan Endang Purwanti ${ }^{1}$ \\ ${ }^{1}$ Departemen Kimia, Institut Teknologi Sepuluh Nopember, \\ Kampus ITS Sukolilo-Surabaya 60111, Indonesia \\ Email:afifah.chem@gmail.com
}

\begin{abstract}
ABSTRAK
Terinspirasi dari sulitnya limbah aluminium terdegradasi dan tidak bisa diuraikan oleh proses biologi di lingkungan, maka limbah aluminium yang sudah terbuang seperti kaleng bekas, aluminium foil pembungkus makanan dan minuman bahkan tidak sedikit limbah laboratorium berpotensi untuk dimanfaatkan kembali.

Pada penelitian ini, limbah aluminium diekstrak menggunakan kalium hidroksida (KOH) dalam kadar dan jumlah tertentu, kemudian direaksikan dengan asam sulfat $\left(\mathrm{H}_{2} \mathrm{SO}_{4}\right)$ dalam kadar dan jumlah tertentu pula. Proses itu menghasilkan kalium aluminium sulfat yang berpotensi sebagai koagulan untuk menjernihkan limbah cair dan air keruh. Kandungan aluminium yang berhasil diperoleh berkisar antara 2,33\% dan 24,07\%, dengan rendemen hasil $81,12 \%$ sampai $97,95 \%$.
\end{abstract}

Kata kunci: Limbah aluminium, Bahan Koagulan, Pengolahan Limbah Cair, Penjernihan Air, Analisis Kualitatif

\section{PENDAHULUAN}

Aluminium merupakan salah satu jenis material yang sangat banyak ditemui dan didapat di sekitar kita dalam bentuk seperti kaleng minuman, komponen elektronik, perabot rumah tangga, siku scrap beberapa jenis bahan bangunan dan bahkan beberapa jenis makanan menggunakan aluminium foil sebagai kemasannya. Terinspirasi dari sulitnya limbah aluminium terdegradasi dan tidak bisa diuraikan oleh proses biologi di lingkungan, maka aluminium yang sudah terbuang atau tidak terpakai berpotesi untuk dimanfaatkan kembali.

Aluminium terindikasi sebagai logam putih, dapat ditempa namun liat; serbuknya menghasilkan warna abu-abu dan akan melebur pada $695^{\circ} \mathrm{C}$; apabila terkena udara maka aluminium akan teroksidasi pada permukaannya, namun demikian lapisan oksida ini melindungi bahan dari oksida lebih lanjut. Aluminium termasuk golongan tervalen dalam senyawa-senyawanya. Ion aluminium $\left(\mathrm{Al}^{3+}\right)$ dapat membentuk garam dengan anionnya. Aluminium sulfat kemungkinan besar dapat membentuk garam rangkap dengan sulfat dari kation-kation monovalen yang dapat berfungsi sebagai koagulan.

Didasarkan atas kenyataan yang ada dalam semua kegiatan Laboratorium, terutama terkait dengan banyaknya limbah yang dihasilkan akibat praktikum yang dilakukan, maka potensi limbah yang dihasilkan juga cukup besar. Dengan demikian upaya untuk pengelolaan dan pengolahan limbah yang benar dan tidak mencemari lingkungan sangat mutlak diperlukan. 
Pada penelitian kali ini dilakukan upaya penanganan limbah padat berupa aluminium dan limbah cair di laboratorium. Selain itu, diusahakan untuk mencari solusi serta pengelolaan limbah dari semua limbah-limbah yang dihasilkan tersebut, baik limbah cair maupun padat (dalam hal ini limbah aluminium).

Tujuan pelaksanaan penelitian ini adalah untuk membantu memberikan solusi teknik pengolahan limbah cair dan penjernihan air yang lebih efektif dan efisien, sesuai PP No 18 tahun 1999 Tentang Pengelolaan Limbah. Kegiatan penelitian ini juga memberikan kontribusi berarti bagi pengembangan IPTEKS dalam bidang pengolahan limbah cair laboratorium dan penjernihan air.

\section{METODA PENELITIAN}

\section{Alat}

Peralatan yang digunakan dalam penelitian yang dilakukan terdiri atas alat-alat gelas (tabung reaksi, erlenmeyer, gelas beker, gelas ukur, pipet tetes, pipet ukur, pipet volum, gelas arloji, batang pengaduk), neraca analitik, corong buchner, gunting, amplas, Spektrofometer serapan atom, Spektrofotometer FTIR, Spektrofotometer UV visible.

\section{Bahan}

Bahan-bahan kimia yang digunakan pada penelitian ini adalah: $\mathrm{HCl}, \mathrm{H}_{2} \mathrm{SO}_{4}, \mathrm{KOH}$, Etanol $95 \%, \mathrm{HNO}_{3}, \mathrm{AlCl}_{3}$, $\mathrm{Na}_{2} \mathrm{CO}_{3}, \mathrm{~K}_{2} \mathrm{CrO}_{4}, \mathrm{AgNO}_{3}$ dan aquademin. Sampel berupa beberapa kaleng bekas, bekas packing aluminium di laboratorium dan limbah aluminium

\section{Pembuatan kalium aluminium}

Sampel disiapkan sebagai sumber aluminium. Untuk jenis kaleng, dibersihkan menggunakan amplas dengan maksud untuk menghilangkan lapisan cat, warna, serta plastiknya; untuk bekas packing aluminium, dicuci bersih dan untuk limbah aluminium dari laboratorium, dibersihkan pengotornya. Sesudah dibersihkan, diperkecil ukurannya dengan cara di potong kecil-kecil dan selanjutnya dimasukkan ke dalam erlenmeyer. Langkah selanjutnya ditambahkan $\mathrm{KOH} 20 \%$ sebanyak $50 \mathrm{~mL} / \mathrm{gr}$ sampel ke erlemeyer dan dipanaskan menggunakan hotplate pada suhu $65^{\circ} \mathrm{C}$. Pemanasan dihentikan hingga gelembung-gelembung gas hilang. Larutan yang diperoleh selanjutnya disaring dan didinginkan, berikutnya ditambahkan $\mathrm{H}_{2} \mathrm{SO}_{4} 6 \mathrm{M}$ sebanyak $30 \mathrm{~mL}$ secara hati-hati sambil diaduk. Setelah itu kembali dilakukan penyaringan. Langkah berikutnya, larutan didinginkan di dalam es. Setelah ditunggu beberapa saat maka kristal yang terbentuk dipisahkan dengan corong buchner dan dicuci dengan $20 \mathrm{~mL}$ etanol $50 \%$. Endapan yang diperoleh selanjutnya dikeringkan, setelah itu ditimbang sampai beratnya konstan.

\section{Penentuan kandungan aluminium dalam kaleng bekas dan limbah aluminium}

Sampel yang berupa endapan hasil penelitian diencerkan 100 kali, sehingga menghasilkan larutan. Selanjutnya larutan yang sudah encer tersebut dianalisis kadar aluminiumnya menggunakan Spektrofometer serapan atom pada panjang gelombang 309,3 nm.

\section{Pengukuran Bobot Jenis.}

Piknometer dalam keadaan kosong ditimbang dan dicatat bobotnya, lalu produk hasil sintesis dimasukkan secara perlahan sehingga menghindari adanya gelembung. Selanjutnya Piknometer ditutup kembali sehingga sebagian produk sintesis keluar melalui lubang bagian atas piknometer. Piknometer yang sudah terisi produk sintesis ditimbang kembali. Pengukuran dilakukan secara triplo.

$$
\text { Bobot jenis }(\mathrm{g} / \mathrm{ml})=\frac{\text { (berat isi }- \text { berat kosong) } \mathrm{g}}{\text { (Volume piknometer) } \mathrm{ml}}
$$




\section{Analisis FTIR}

Analisis menggunakan FTIR bertujuan untuk mengetahui gugus fungsi yang terdapat pada koagulan hasil sintesis. Penentuan spektrofotometri IR dilakukan pada rentang panjang gelombang $4000-400 \mathrm{~cm}^{-1}$ dengan resolusi $8(1 / \mathrm{cm})$. Preparasi dilakukan dengan cara mencampurkan sampel koagulan hasil sintesis sebanyak $4 \mathrm{mg}$ dengan $100 \mathrm{mg}$ serbuk $\mathrm{KBr}$ untuk selanjutnya dibuat pelet.

\section{Daya koagulasi hasil penelitian}

Kualitas produk hasil penelitian diterapkan sifat koagulannya terhadap limbah cair dan air sungai dengan metode turbidimetri. Produk hasil penelitian ditimbang sebanyak 0,5 g dan $1 \mathrm{~g}$ kemudian dimasukkan dalam labu erlemeyer yang berisi $250 \mathrm{~mL}$ limbah cair dan air selokan yang telah diukur tingkat kekeruhannya, diaduk menggunakan magnetik stirer beberapa saat kemudian dibiarkan \pm 60 menit dengan maksud agar kotoran yang ada mengendap. Air tersebut selanjutnya diukur tingkat kekeruhannya dengan menggunakan metode turbidimetri.

\section{HASIL DAN PEMBAHASAN}

Koagulan merupakan bahan kimia yang memiliki kemampuan untuk menetralkan muatan koloid dan mengikat partikel yang ada sehingga menyebabkan terjadinya pembentukan flok. Cukup banyak jenis koagulan; salah satunya adalah koagulan yang berbasis aluminium. Beberapa diantaranya adalah aluminium sulfat dan polialuminium klorida yang penggunaannya lebih luas dalam proses pengolahan air baku maupun air limbah (Badan Standardisasi Nasional., 1995) (Zouboulis et al. 2010).

Pada proses pembuatan koagulan, saat $\mathrm{KOH} 20 \%$ ditambahkan terjadi reaksi cepat dan bersifat eksoterm. Reaksi yang terjadi adalah :

$$
2 \mathrm{Al}+2 \mathrm{KOH}+6 \mathrm{H}_{2} \mathrm{O} \rightarrow 2 \mathrm{~K}\left[\mathrm{Al}(\mathrm{OH})_{4}\right]+3 \mathrm{H}_{2}
$$

Pada reaksi tersebut gas $\mathrm{H}_{2}$ dilepaskan, kondisi tersebut ditandai dengan adanya gelembung-gelembung gas seiring berlangsungnya reaksi, gas tersebut akan habis setelah semua aluminium yang ada bereaksi. Untuk menghindari terbentuknya $\mathrm{Al}(\mathrm{OH})_{3}$ maka $\mathrm{KOH} 20 \%$ ditambahkan berlebih. Pada kondisi ini, dilakukan pemanasan guna mempercepat terjadinya reaksi. Filtrat yang dihasilkan ditambah $\mathrm{H}_{2} \mathrm{SO}_{4} 6 \mathrm{M}$ dan selanjutnya disaring sehingga semua pengotornya hilang. Reaksi yang terjadi adalah :

$$
2 \mathrm{~K}\left[\mathrm{Al}(\mathrm{OH})_{4}\right]+\mathrm{H}_{2} \mathrm{SO}_{4} \rightarrow 2 \mathrm{Al}(\mathrm{OH})_{3}+\mathrm{K}_{2} \mathrm{SO}_{4}+2 \mathrm{H}_{2} \mathrm{O}
$$

Penambahan larutan $\mathrm{H}_{2} \mathrm{SO}_{4}$ dimaksudkan supaya seluruh $\mathrm{K}\left[\mathrm{Al}(\mathrm{OH})_{4}\right]$ bereaksi sempurna. $\mathrm{Al}(\mathrm{OH})_{3}$ yang dihasilkan langsung bereaksi dengan $\mathrm{H}_{2} \mathrm{SO}_{4}$ atas dasar persamaan reaksi berikut :

$$
2 \mathrm{Al}(\mathrm{OH})_{3}+3 \mathrm{H}_{2} \mathrm{SO}_{4} \rightarrow \mathrm{Al}_{2}\left(\mathrm{SO}_{4}\right)_{3}+6 \mathrm{H}_{2} \mathrm{O}
$$

Pada reaksi yang telah terjadi sebelumnya, penambahan $\mathrm{H}_{2} \mathrm{SO}_{4}$ mengakibatkan terbentuknya $\mathrm{Al}(\mathrm{OH})_{3}$ bersama-sama dengan $\mathrm{K}\left[\mathrm{Al}(\mathrm{OH})_{4}\right]$, namun setelah jumlahnya berlebih maka $\mathrm{H}_{2} \mathrm{SO}_{4}$ melarutkan $\mathrm{Al}(\mathrm{OH})_{3}$ menjadi $\mathrm{Al}_{2}\left(\mathrm{SO}_{4}\right)_{3}$ berupa larutan tak berwarna alias bening. Senyawa $\mathrm{Al}_{2}\left(\mathrm{SO}_{4}\right)_{3}$ yang terbentuk bereaksi kembali dengan $\mathrm{K}_{2} \mathrm{SO}_{4}$ dihasilkan kristal yang diperkirakan adalah $\mathrm{KAl}\left(\mathrm{SO}_{4}\right)_{2} \cdot 12 \mathrm{H}_{2} \mathrm{O}$ berwarna putih. Reaksi yang terjadi adalah :

$$
\mathrm{K}_{2} \mathrm{SO}_{4}+\mathrm{Al}_{2}\left(\mathrm{SO}_{4}\right)_{3}+12 \mathrm{H}_{2} \mathrm{O} \rightarrow 2 \mathrm{KAl}\left(\mathrm{SO}_{4}\right)_{2} \cdot 12 \mathrm{H}_{2} \mathrm{O}
$$


Kristal koagulan hasil sintesis yang diperoleh selanjutnya dicuci menggunakan larutan etanol $50 \%$ untuk menyerap kelebihan air dan mempercepat pengeringan.

Hasil koagulan sintesis selanjutnya dianalisa FTIR untuk melihat gugus fungsi yang dihasilkan. Hasil yang diperoleh dinyatakan pada Gambar 1.
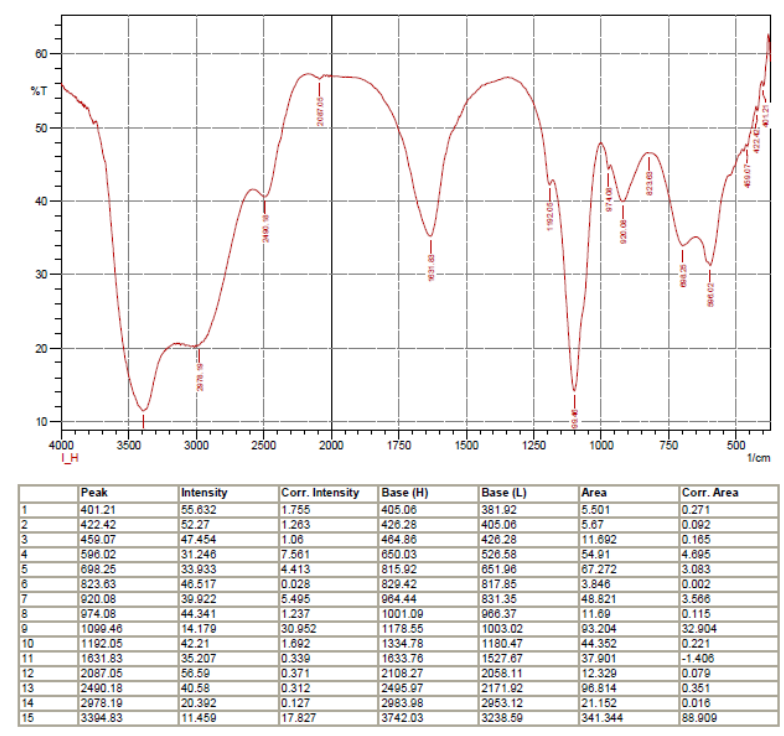

Gambar 1: Hasil analisis FTIR

Spektra FTIR koagulan yang dihasilkan menunjukkan adanya serapan pada daerah bilangan gelombang 3394,83 yang merupakan pencirian vibrasi ulur gugus $\mathrm{OH}$-hidroksil. Pita serapan pada daerah 1631,83 $\mathrm{cm}^{-1}$ menunjukkan gugus $\mathrm{OH}$ yang terikat pada molekul air kristal bebas. Hal tersebut berdasarkan pada pencirian koagulan berbasis aluminium yang telah ditemukan oleh Tzoupanos et al. (2009) yang mana dinyatakan bahwa pita serapan pada panjang gelombang sekitar $1600 \mathrm{~cm}^{-1}$ berkaitan dengan molekul air kristal bebas, sedangkan pada panjang gelombang sekitar $3600-3400 \mathrm{~cm}^{-1}$ menunjukkan adanya gugus$\mathrm{OH}$ yang berinteraksi pada gugus hidroksil, molekul air, ataupun ion-ion natrium. Vibrasi ulur untuk molekul air pada koagulan sintetis terbentuk pada panjang gelombang $2978,19 \mathrm{~cm}^{-1}$. Pita serapan PAC

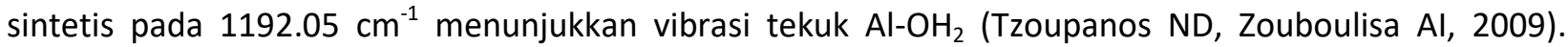
Secara umum, koagulan hasil sintesis menunjukkan karakteristik polialuminium yang khas dan bisa dikatakan bahwa sintesis koagulan dari limbah aluminium berhasil dilakukan.

Kandungan aluminium yang berhasil diperoleh dari hasil analisa AAS berkisar antara 2,33\% dan 24,07\%; dengan rendemen hasil $81,12 \%$ sampai $97,95 \%$. Sedangkan hasil uji daya koagulasi menunjukkan bahwa penambahan 0,25 gram koagulan mampu menurunkan kekeruhan hingga $45 \%$ dan pada penambahan koagulan 2 kali lipat berhasil menurunkan kekeruhan hingga 70\%. Hal ini menunjukkan bahwa koagulan sintesis yang diperoleh mempunyai kinerja yang efektif sebagai koagulan untuk penjernih air dan limbah cair.

\section{KESIMPULAN}

Koagulan berbasis aluminium yang dari limbah aluminium berhasil disintesis dengan metode hidrolisis parsial. Karakterisasi yang telah dilakukan menunjukkan sifat spesifik aluminium sebagai koagulan. Kadar 
aluminium maksimum yang berhasil diperoleh sebesar 24,07\%; dengan rendemen hasil hingga 97,95\%. Hasil uji daya koagulasi menunjukkan bahwa penambahan koagulan 0,5 gram mampu menurunkan kekeruhan hingga $70 \%$.

\section{DAFTAR PUSTAKA}

Badan Standardisasi Nasional. (1995). Polialuminium klorida. jAKARTA: Departemen Perdagangan.

Tzoupanos ND, Zouboulisa AI, T. C. (2009). A systematic study for the characterization of a novel coagulant (polyaluminium silicate chloride). J Phy Eng., 324, 30-39.

Babu, R. and Chaudhuri, M. (2005) Home Water Treatment by Direct Filtration with Natural Coagulant. Journal of Water and Health , 3, 27-30.

Badan Standardisasi Nasional. (1995). SNI 06-3822-1995, Polialuminium klorida. Jakarta: Departemen Perdagangan.

Bina B, Mehdinejad MH, Nikaeen M, Attar HM. (2009). Effectiveness of chitosan as natural coagulant aid in treating turbid waters. Iran J Environ Health Sci. Eng. 6:247-252.

Davis, M.L. and Cornwell, D.A. (2008) Introduction to Environmental Engineering. McGraw-Hill Companies, New York.

Departemen Kesehatan. (1990). Peraturan Menteri Kesehatan Republik Indonesia Nomor 416/MEN.KES/PER/IX/1990 tentang Syarat-syarat dan Pengawasan Kualitas Air

Fei HE, Jia ZQ, Peng YL, Wang PJ, Liu ZZ. (2004). A novel method to synthesize polyaluminium chloride with a membran reactor. J Enviromental Sci. 16(3):482-486.

Gao BY, Chu YB, Yue QY, Wang BJ, Wang SJ. (2005). Characterization and coagulation of a polyaluminium chloride (PAC) coagulant with high $\mathrm{Al}_{13}$ content. J Environmental Management 76(2):143-147.

Libanius, M. (2008). Fundamentals of Quality and Water Treatment. Atom Ed, Campinas.

Rinaldi DP. (2009). Pemanfaatan limbah industri logam aluminium sebagai bahan baku polialuminium klorida dalam menurunkan kekeruhan limbah industri tekstil. Bogor (ID): Institut Pertanian Bogor.

Risdianto D. (2007). Optimisasi proses koagulasi flokulasi untuk pengolahan air limbah industri jamu. Studi kasus: PT Sido Muncul . Semarang (ID): Universitas Diponegoro.

Shen YH, Dempsey BA. (1998). Syhntesis and speciation of polyaluminium chloride for water treatment. J Enviromental Intl. 24:889-910.

Tzoupanos ND, Zouboulisa Al, Tsoleridis CA. (2009). A systematic study for the characterization of a novel coagulant (polyaluminium silicate chloride). J Phy Eng. 342:30-39.

Zoubulis Al, Tzoupanos N. (2010). Alternative cost-effective preparation method of polyaluminium chloride (PAC) coagulant agent: Characterization and comparative application for water/wastewater treatment. J Desalination 250:339-344. 